\title{
Dynamics of Fisheries that Affect the Population Growth Rate Coefficient
}

\author{
A. L. JENSEN \\ School of Natural Resources \\ University of Michigan \\ Ann Arbor, Michigan 48109
}

ABSTRACT / Conventional surplus production models indicate that destruction of fish populations by overfishing is difficult, if not impossible, but catastrophic declines in abundance of exploited populations are common. Surplus production models also do not predict large continuing fluctuations in yield, but large fluctuations in yield are common. Conventional surplus production models assume that fish- eries do not impact the population's capacity to increase, but changes in age structure or a decrease in age-specific fecundity resulting from fishing can decrease the coefficient of increase. A surplus production model is developed in which fishing reduces the capacity of a population to increase; the model is applied to describe the fluctuations observed in yield of lake herring (Coregonus artedii) from the upper Great Lakes. The fisheries of the Great Lakes were decimated by the combined effects of heavy fishing and a changing environment. For some species, yield increased to high levels and then the fisheries collapsed; for other species, yield and effort fluctuated greatly.
Conventional surplus production models for management of fisheries indicate that fish populations are difficult to destroy through overexploitation (Pella and Tomlinson 1969), but many fish populations have collapsed and abundance often varies greatly as a result of heavy exploitation. For example, changes in the commercial fisheries of the Great Lakes have been dramatic, with wide fluctuations in yield and extinction of several species that were commercially important (Smith 1968, Christie 1974). There is a tendency to attribute such catastrophic variation in catch to environmental factors. This occurs in part, perhaps, because such events are not predicted by conventional fishery models. A minor modification in the logistic surplus production model, a modification in which fishing has an impact on the capacity of a population to increase, results in a model that predicts large fluctuations in yield. The new model is developed and its properties are compared with those of the logistic surplus production model. Both models are applied to describe the dynamics of the lake herring (Coregonus artedii) fishery in the upper Great Lakes.

\section{The Great Lakes Fisheries}

Many changes have occurred during the past 100 years in the fish populations and the fisheries of the Great Lakes (Berst and Spangler 1973, Wells and McLain 1973, Lawrie and Rahrer 1973). In the upper Great Lakes, that is, Lake Superior, Lake Huron, and Lake Michigan, the commercial fisheries have caught mostly lake trout (Salvelinus namaycush), lake whitefish (Coregonus clupeaformis), chubs (Coregonus spps.), and lake herring (Coregonus artedii). Lake trout supported a large and stable fishery in the upper Great Lakes for many decades before the combined impacts of sea lamprey (Petromyzon marinus) predation and heavy exploitation

KEY WORDS: Fisheries Management; Lake Herring; Lake Michigan; Surplus production destroyed the stocks (Smith 1968, Jensen 1978). Lake trout were exterminated in Lake Michigan, and the population is now maintained entirely by stocking. In the other two lakes, small populations of native stocks survived, but these lakes are stocked extensively to maintain fishable populations of lake trout.

Yield of lake whitefish was more variable than yield of lake trout; lake whitefish yield in many areas has a tendency to increase gradually to a maximum and then collapse (Jensen and Buettner 1976).

The early chub fishery consisted of several different species, but most of these are now extinct, and the fishery is supported by a single species (Coregonus hoyi). In Lake Superior and Lake Huron, chub yields have fluctuated in a regular pattern of steep peaks and valleys. In Lake Michigan, there was an irregular increase to a maximum in 1958 and then a decline. The fishery was closed in the 1970 s to save the remnants of the stock. Closure of the fishery has resulted in substantial recovery of the population.

Yield of lake herring from Lake Superior increased from near zero in 1895 to a peak in the early 1940s and then gradually declined. In Lake Michigan, the pattern is different, showing high yields in the early 1900 s, a stable fishery for a few years, and then a decline toward zero in 1960. In Lake Huron, yields of herring fluctuated regularly from 1910 into the late 1930s; then yield decreased rapidly and did not recover.

For the Great Lakes fisheries, as for other fisheries that have collapsed under heavy fishing pressure, it is difficult to assess the relative importance of fishing and environmental factors. Along with the changes in natural populations, an invasion of sea lamprey has helped to devastate the lake trout and lake whitefish populations (Smith 1968). Invading alewife (Alossa pseudoharengus) and smelt (Osmerus mordax) populations may have preyed upon or competed with natural stocks 
(Smith 1968). Major environmental changes and contamination could also have decreased fertility. Fishing, however, has had a major impact on the Great Lakes fisheries (Smith 1968, Jensen 1976 and 1978).

\section{The Models}

Conventional surplus production models assume that fish populations have a capacity to increase and that this capacity is some function of population size; the capacity to increase is assumed to be a maximum at some intermediate population size. Assuming that a fishery operates on a population through removal of biomass at the rate $d Y / d t=q E B$, and that the biomass dynamics of an unexploited fishery are described by the logistic equation, gives the model

$$
\begin{aligned}
& d Y / d t=q E B \\
& d B / d t=k B-k B^{2} / B_{\infty}-q E B
\end{aligned}
$$

where $Y$ is the cumulative yield from the fishery, $k$ is the population growth coefficient, $B_{\infty}$ is the carrying capacity of the environment in terms of biomass, $q$ is the catchability coefficient, and $E$ is the fishing effort.

This logistic surplus production model was developed by Volterra (1928), Hjort and others (1933), Graham (1935), and Schaefer (1954). It has been widely applied for stock assessment (Ricker 1975, Gulland 1972 and 1977, Jensen 1976 and 1978, Abramson and Tomlinson 1972, and MacCall and others 1976), for environmental impact assessment (Jensen 1982, Jensen and others 1982), and for assessment of the impact of toxicants on populations (Jensen and Marshall 1982 and 1983).

Properties of the logistic surplus production model that are important for stock assessment are well known. The relation between annual sustainable yield $Y_{e}$ and biomass is the parabola

$$
Y_{e}=k B-k B^{2} / B_{\infty} .
$$

For every value of fishing effort $E$ such that $q E<k$, the population approaches an equilibrium biomass of

$$
B=B_{\infty}(k-q E) / k \text {. }
$$

The maximum sustainable yield of $k B_{\infty} / 4$ occurs at a biomass of $B_{\infty} / 2$, a fishing effort of $k / 2 q$, and a fishing mortality coefficient of $k / 2$. The relation between annual sustainable yield and fishing effort is the parabola

$$
Y_{e}=B_{\infty} q E-\left(B_{\infty} q^{2} / k\right) E^{2} .
$$

In the logistic surplus production model, it is assumed that fishing has no impact on the population growth coefficient $k$. If fish are caught before they spawn or if fishing alters the age structure, fishing could decrease the population growth coeffi-
Table 1. Population age structure and fecundity with two different total mortality rates, $Z$.

\begin{tabular}{cccc}
\hline Age, $x$ & $l(x), Z=0.80$ & $l(x), Z=1$ & $m(x)$ \\
\hline 0 & 1.0000 & 1.0000 & 0 \\
1 & 0.4493 & 0.3679 & 0 \\
2 & 0.2019 & 0.1353 & 8 \\
3 & 0.0907 & 0.0479 & 15 \\
4 & 0.0407 & 0.0183 & 18 \\
5 & 0.0183 & 0.0067 & 20 \\
6 & 0.0082 & 0.0025 & 25 \\
\hline
\end{tabular}

cient $k$. This is shown below for the effect of fishing on age structure. The biomass equation of the surplus production model is closely related to the population growth equation

$$
d N / d t=r N-r N^{2} / K
$$

where $N$ is abundance in numbers, $r$ is the rate of increase in an uncrowded environment, and $K$ is the carrying capacity in terms of numbers (Slobodkin 1962). Applying the relation $B=$ $N W$, where $W$ is average individual weight, it can be shown that if $d W / d t=0$, then $r=k$. The value of $r$ can be determined from a combined life and fecundity table with the equation

$$
\int_{0}^{\infty} e^{-r x} l(x) m(x) d x=1
$$

where $m(x)$ is the age specific fecundity and $l(x)$ is the probability of survival of age $x$ (Slobodkin 1962).

The age structure and a fecundity schedule for a hypothetical fish population with a total mortality rate $Z$ of 0.80 are given in Table 1. For this population, $r=0.50$. If a fishery is applied such that the total mortality rate is increased to 1.0 , the age structure changes to that given in the third column of Table 1 , and $r$ decreases to 0.27 . A change in the age structure caused by fishing results in a decrease in $r$. A decrease in $r$ as a result of environmental stress has been demonstrated in laboratory experiments; for example, Bertram and Hart (1979) reported that for Daphnia pulex, as cadmium concentration increased from $0 \mu \mathrm{g} / \mathrm{l}$ to $10 \mu \mathrm{g} / \mathrm{l}, r$ decreased from 0.31 to nearly zero.

A simple model that incorporates the impact of fishing on the capacity of a population to increase is

$$
\begin{aligned}
& d Y / d t=q E B \\
& d B / d t=\left(k-g Y_{t}\right) B\left(B_{\infty}-B\right) / B_{\infty}-q E B
\end{aligned}
$$

where $g Y_{t}<k$ and $Y_{t}$ is the annual yield of the previous year, which is given as

$$
Y_{t}=\int_{t-1}^{t} q E B d x .
$$

For this model, the relation between annual yield and biomass under equilibrium conditions, where $d B / d t=0$ and yield of 
the present year equals yield of the past year, is given by the equation

$$
Y_{e}=\frac{k B-k B^{2} / B_{\infty}}{1+g B-g B^{2} / B_{\infty}} .
$$

The biomass at which the maximum sustainable yield occurs is $B_{m s y}=B_{\infty} / 2$, which is the same as for the logistic model. The maximum sustainable yield is

$$
M S Y=k B_{\infty} /\left(g B_{\infty}+4\right)
$$

which is smaller than for the logistic model, and the fishing effort at which the $M S Y$ occurs is

$$
E_{m s y}=2 k / q\left(g B_{\infty}+4\right) .
$$

The models will be applied to simulate the development of fisheries over time. The simplest method for this simulation is to write the models in terms of difference equations. The difference equation form of the logistic surplus production model is

$$
\begin{aligned}
Y_{t} & =q E_{t} B_{t} \\
B_{t} & =B_{t-1}+k B_{t-1}-k B_{t-1}^{2} / B_{\infty}-q E_{t-1} B_{t-1}
\end{aligned}
$$

and the difference equation form of the model with an impact of fishing on the capacity of a population to increase is

$$
\begin{aligned}
Y_{t}= & q E_{t} B_{t} \\
B_{t}= & B_{t-1}+\left(k-g Y_{t-1}\right) B_{t-1} \\
& \cdot\left(B_{\infty}-B_{t-1}\right) / B_{\infty}-q E_{t-1} B_{t-1} .
\end{aligned}
$$

In development and application of conventional surplus production models, fishing effort is an exogenous variable and its dynamics are not described. This approach is adequate for study of the equilibrium properties of fisheries, but to model the dynamics of a fishery over time, it is necessary to describe the dynamics of fishing effort. For the Great Lakes fisheries, the relation between yield and effort is linear (Jensen and Buettner 1976, and Figure 1), and fishing effort is also linearly related to yield of the previous year. This relation is applied for dynamic simulation of the lake herring fishery.

\section{Results and Discussion}

The models were applied to simulate the dynamics of the lake herring fishery of the upper Great Lakes. The lake herring life history indicates that it is vulnerable to an impact of fishing on the rate of increase. Lake herring are readily available to fishermen during the spawning season when, just prior to spawning, they concentrate in large numbers on small spawning areas; the entire catch in Wisconsin waters of Lake Superior consisted of fish that had not spawned (Selgeby 1982).

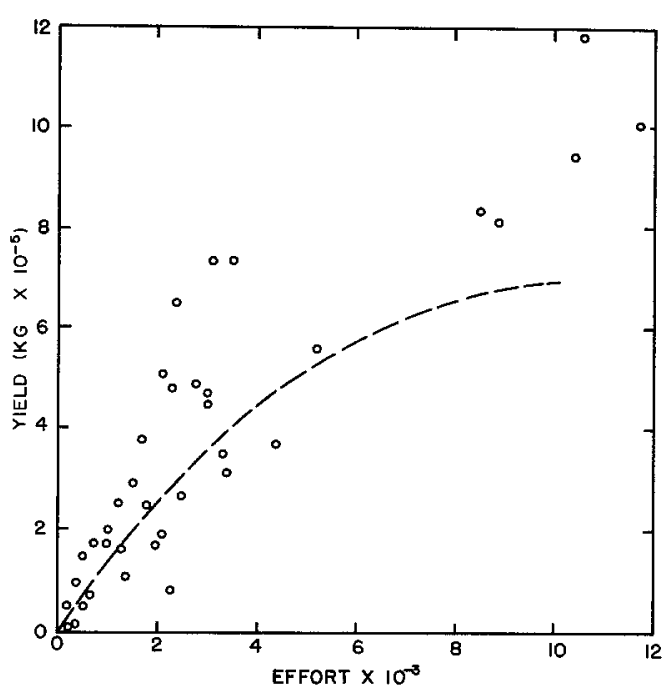

Figure 1. Observed catch and effort data for lake herring of district MS-4. The curve is the fitted logistic surplus production model.

Catch in other areas also was mostly fish that had not yet spawned (Wells and McLain 1983). Such a fishery results in production of fewer eggs by the population and possibly a reduction in age-specific fecundity; this could cause a decrease in $k$. The fishery also causes a large change in the age structure of the herring population. Age structures during a period of recovery from heavy exploitation for an area of Lake Superior are listed in Table 2. During the 1950s the stock was heavily fished and seriously depleted (Bails and Patriarche 1974). In 1960 , more than one half of the exploited stock was of age 4, but the stock recovered and the proportions of older individuals gradually increased.

Extensive catch and effort data are available for estimation of parameters. The state of Michigan waters of Lakes Superior, Huron, and Michigan have been divided into 27 fishery statistical districts (Hile 1962), and monthly commercial catch and effort data have been collected for these districts since 1929 (Jensen and Buettner 1976).

Estimation of the parameters of surplus production models with catch and effort data is difficult because the model is not linear and when linearized the resulting equation seriously violates the assumptions of non-multicolinarity and statistical independence. Therefore, nonlinear least squares was applied using an iterative approach (Pella and Tomlinson 1969) to fit the models of the $2^{\prime \prime}(5.06-\mathrm{cm})$ mesh gill net data for district MS-4 of Lake Superior (Figure 1). To fit the logistic model, the parameters $B_{\infty}, k$, and $q$ were first estimated as recommended by Pella and Tomlinson (1969): $B_{\infty}=4$ times the maximum catch, $q=$ maximum catch per unit of effort divided by $B_{\infty}, E_{m s y}=$ average effort, and $k=2 q E_{m s y}$. These initial 
Table 2. Change in percentage age composition of fall catch of lake herring from Keweenaw Bay area of Lake Superior (Bails and Patriarche 1974).

\begin{tabular}{cccc}
\hline Age & 1960 & 1965 & $1971^{1}$ \\
\hline 3 & 10 & 4 & 4 \\
4 & 53 & 36 & 12 \\
5 & 24 & 36 & 28 \\
6 & 10 & 21 & 34 \\
7 & 4 & 9 & 19 \\
8 & - & 1 & 3 \\
9 & - & - & 1 \\
\hline
\end{tabular}

${ }^{1} 1970$ was not sampled.

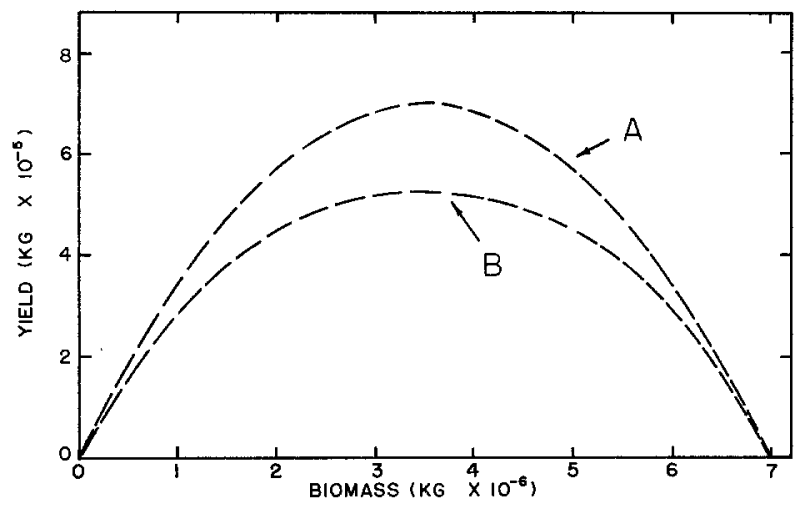

Figure 2. Equilibrium yield curves for the logistic surplus production model (curve A) and for the new surplus production model (curve B).

estimates were $B_{\infty}=4.4 \times 10^{6} \mathrm{~kg}, q=0.00002$, and $k=0.23$. The parameter values that gave the best fit were then determined iteratively as $B_{\infty}=7 \times 10^{6} \mathrm{~kg}, k=0.40$, and $q=$ 0.00002 .

A regression of yield on effort for district MS-4 gave $Y_{i}=$ $105.25 E_{t}$ with $P<0.0001$ and $R^{2}=0.79$. The regression of effort on the yield of the previous year, $E_{t+1}=0.0079 Y_{t}$, is not as good but it is still significant with $P<0.0001$ and $R^{2}=0.62$. For simulations, the parameter $g$ and the parameter relating effort to catch of the previous year were adjusted to give the best fit of the new model to the observations for district MS-4, and this gave $2 \times 10^{-7}$ and 0.012 .

The equilibrium stock production curve for the logistic surplus production model, which is a parabola, and the observed catch and effort data appear in Figure 1. The model fits the data, but the data are not from an equilibrium fishery. The $M S Y$ is $7 \times 10^{5} \mathrm{~kg}$ and occurs at a fishing effort of 10,000 units and a biomass of $3.5 \times 10^{6} \mathrm{~kg}$. Several of the observed yields are higher than the $M S Y$.

The equilibrium stock production curve for the new model is similar in shape to a parabola (Figure 2), but the top is flattened and the sustainable yields are lower as compared with

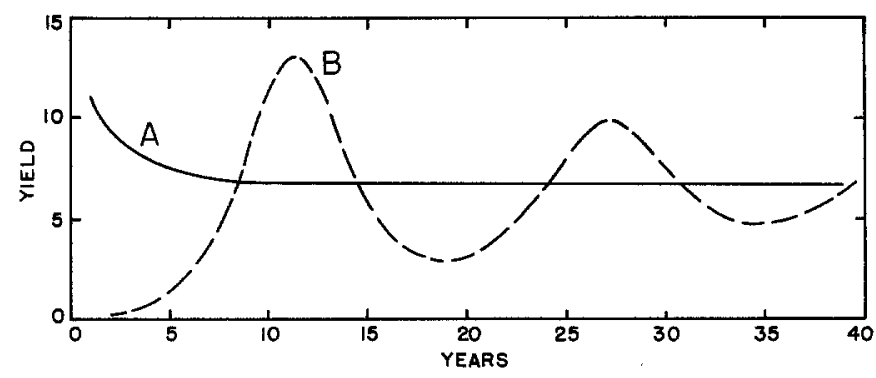

Figure 3. Yields generated by the logistic model with: (A) constant effort and (B) effort proportional to yield of the previous year.

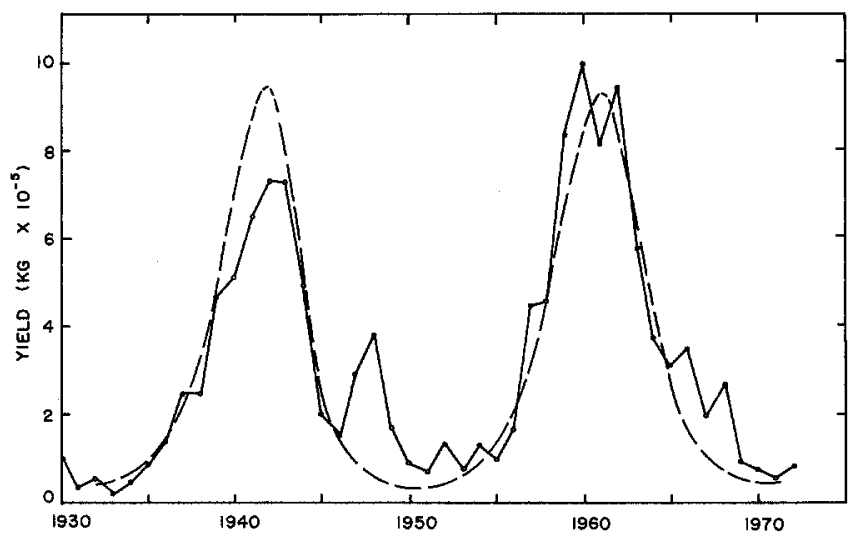

Figure 4. Observed catch of lake herring with $2^{\prime \prime}(5.06-\mathrm{cm})$ gill nets in Lake Superior fishery district MS-4 and predicted yield (dashed line).

the logistic equation. The $M S Y$ is $518,518 \mathrm{~kg}$ and occurs at a fishing effort of 9090 units. The biomass at which the $M S Y$ occurs is the same as for the logistic equation.

To simulate the dynamic behavior of a developing herring fishery, the discrete time form of the logistic surplus production model was applied to generate yield from a fishery over time with both a constant effort and with effort changing linearly with yield of the previous year (Figure 3). If fishing effort is constant, the logistic surplus production model predicts that yield will begin high as the stock is fished up and then decrease asymptotically toward an equilibrium (Figure 3). If effort is proportional to yield of the previous year, yield fluctuates but the fluctuations rapidly decrease in amplitude and yield approaches an equilibrium (Figure 3). This result is expected when the sustainable yield is unknown and a fishery is allowed to adjust itself, controlled by the relation between yield of one year and effort of the following year. Comparison of the yield curve for effort proportional to yield with the yield curve for constant effort (Figure 3) indicates that the widely practiced policy of adjusting fishing effort as yield changes tends to produce an unstable fishery with fluctuating yield.

Simulation of the lake herring fishery with the new model 


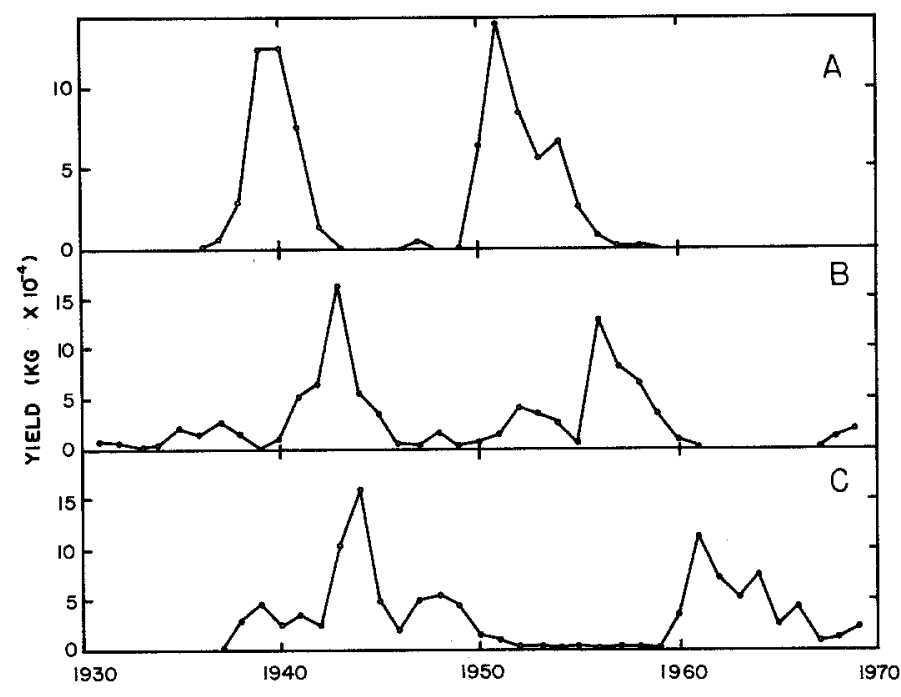

Figure 5. Observed yield of lake herring from districts $\mathrm{MH}-3$ in Lake Huron, MM-3 in Lake Michigan, and MS-5 in Lake Superior.

gives cycles in yield that closely fit the data for statistical district MS-4 (Figure 4). Initially yield and effort are low and population density is high. As the fishery expands, yield and effort increase to a maximum as the population biomass decreases. Yield begins to decrease after fishing has decreased the biomass, and then fishing effort decreases. The stock recovers after yield and effort both become low and then the cycle begins again. Fisheries that impact on the rate of increase may not attain an equilibrium.

There have been regular increases and decreases in lake herring yield from Lake Huron, but for Lakes Superior and Michigan there is little indication of regular fluctuations in total yield although yield varies widely. Yield for many individual districts of all three lakes fluctuates in a pattern similar to that predicted by the new model (Figures 4 and 5). Selgeby (1982) reported that the fluctuations in yield from individual spawning areas are lost when district totals are calculated. Loss of the variation of individual spawning stocks in the data for total yield results from the sequential operation of the fisheries (Selgeby 1982). The fish are concentrated in certain areas and the more accessible of these areas are exploited first; as the resource in the accessible areas is depleted, more remote areas are exploited. As yield decreases in some areas, yield increases in others so that large fluctuations in yield on a local scale smooth into relatively small fluctuations in yield when totaled over a large area. The observed fluctuations in lake herring yield are not as smooth as those predicted by the model; a large number of factors determine both the abundance of fish and the level of fishing effort. These factors include environmental variation and economic, political, and social forces. It is

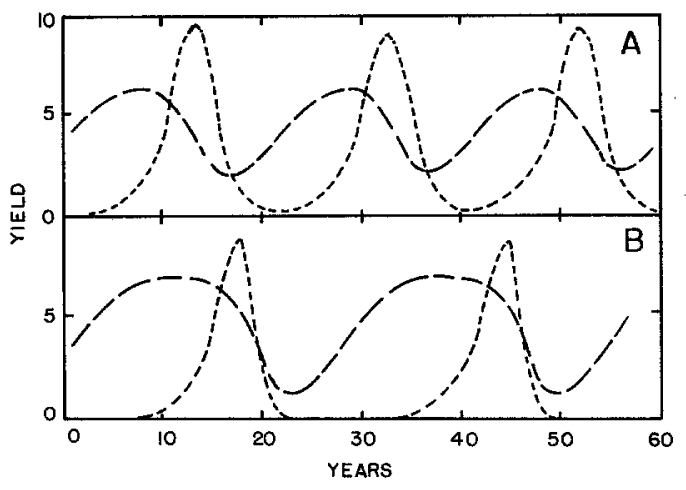

Figure 6. Yield and biomass generated by the new model with different values of the parameters $g:(\mathbf{A}) g=5 \times 10^{-7}$ and $(\mathbf{B}) g=1 \times$ $10^{-5}$.

possible that as a result of random variation a stock may not recover after severe depletion.

Different patterns in yield and biomass are obtainable by variation of the coefficient for impact of fishing on the rate of increase. For example, an increased impact results in a more abrupt decrease in biomass, a sharper collapse in yield, and a longer recovery period (Figure 6).

\section{Literature Cited}

Abramson, N. J., and P. K. Tomlinson. 1972. An application of yield models to a Cialifornia ocean shrimp population. Fishery Bulletin 70:1021-1041.

Bails, J. D., and M. H. Patriarche. 1974. Status of selected fish stocks in Michigan's Great Lakes waters and recommendations for commercial harvest. Michigan Department of Natural Resources Tech. Rept. 73-10, 11, 32, and 33. Lansing, MI.

Berst, A. H., and G. R. Spangler. 1973. Lake Huron, the ecology of the fish community and man's effects on it. Great Lakes Fishery Commission Tech. Rept. No. 21, Ann Arbor, MI. 41 pp.

Bertram, P. E., and B. A. Hart. 1979. Longevity and reproduction Daphnia pulex (DeGeer) exposed to cadmium-contaminated food or water. Environ. Pollut. 19:295-305.

Ghristie, W. J. 1974. Changes in the fish species composition of the Great Lakes. J. Fish. Res. Board Can. 31:827-854.

Graham, M. 1935. Modern theory of exploiting a fishery, and application to North Sea trawling. J. Cons. Int. Explor. Mer. 10:264-274.

Gulland, J. A. 1972. Population dynamics of world fisheries. University of Washington Press, Seattle, WA. 335 pp.

Gulland, J. A. 1977. Fish population dynamics. John Wiley \& Sons, New York, NY. 372 pp.

Hile, R. 1962. Collection and analysis of commercial fishery statistics in the Great Lakes. Great Lakes Fishery Commission Tech. Rept. No. $5.31 \mathrm{pp}$.

Hjort, J., G. John, and P. Ottestad. 1933. The optimum catch. Hvalradets Skr. 7:92-127. 
Jensen, A. L. 1976. Assessment of the United States' lake whitefish (Coregonus clupeaformis) fisheries of Lake Superior, Lake Michigan and Lake Huron. J. Fish. Res. Board Can. 33:747-759.

Jensen, A. L. 1978. Assessment of the lake trout fishery in Lake Superior: 1929-1950. Trans. Am. Fish. Soc. 107:543-549.

Jensen, A. L. 1982. Impact of a once through cooling system on the yellow perch stock in the western basin of Lake Erie. Int. J. Ecol. Modelling 1:155-162.

Jensen, A. L., and H. J. Buettner. 1976. Lake trout, whitefish, chubs, and lake herring yield and effort data for State of Michigan waters of the upper Great Lakes: 1929-1973. Michigan Sea Grant Tech. Rep. No. 52. Ann Arbor, MI. 85 pp.

Jensen, A. L., S. A. Spigarelli, and M. M. Thommes. 1982. Use of conventional fishery models to assess entrainment and impingement of three Lake Michigan fish species. Trans. Am. Fish. Soc. 111:21-34.

Jensen, A. L., and J. S. Marshall. 1982. Application of a Surplus production model to assess environmental impacts on exploited populations of Daphnia pulex in the laboratory. Environ. Pollut. (Series A) 28:273-280.

Jensen, A. L. 1983. Toxicant-induced fecundity compensation: a model of population responses. Environmental Management 7:171-175.

Lawrie, A. H., and J. F. Rahrer. 1973. Lake Superior, a case history of the lake and its fisheries. Great Lakes Fishery Commission Tech. Rept. No. 19.69 pp.

MacCall, A. D., G. D. Stauffer, and J. Troadec. 1976. Southern California recreational and commercial marine fisheries. Marine Fisheries Review 38:1-32.

Pella, J. J., and P. K. Tomlinson. 1969. A generalized stock production model. Inter. Amer. Trop. Tuna Comm. Bull. 13:419496.

Ricker, W. E. 1975. Computation and interpretation of biological statistics of fish populations. Fish. Res. Board Can. Bull. No. 191. Ottawa. 382 pp.

Schaefer, M. B. 1954. Some aspects of the dynamics of populations important to the management of the commercial marine fisheries. Inter. Amer. Trop. Tuna Comm. Bull. 1:27-56.

Selgeby, J. H. 1982. Decline of lake herring (Coregonus artedii) in Lake Superior: an analysis of the Wisconsin herring fishery, 1936-1978. Can. J. Fish. Aquat. Sci. 39:554-563.

Slobodkin, L. B. 1962. Growth and regulation of animal populations. Holt, Rinehart and Winston, New York, NY. 184 pp.

Smith, S. H. 1968. Species succession and fishery exploitation in the Great Lakes. J..Fish. Res. Board Can. 25:667-693.

Volterra, V. 1928. Variations and fluctuations of the number of individuals in animal species living together. J. Cons. Expl. Mer. 3:1-51.

Wells, L., and A. L. McLain. 1973. Lake Michigan, man's effects on the native fish stocks and other biota. Great Lakes Fishery Commission Tech. Rep. No. 20. 55 pp. 